\title{
Movilizaciones sociales y uso político del patrimonio en el Chile contemporáneo
}

\author{
Mauricio Lorca | doctor en gestión de la cultura y el patrimonio, Universidad de Barcelona \\ URL de la contribución <www.iaph.es/revistaph/index.php/revistaph/article/view/3811>
}

Durante los últimos años, Chile ha estado marcado por movilizaciones orientadas a revertir problemáticas relacionadas con falencias en la gestión pública, normativas deficientes, una desigual distribución de la riqueza y de los bienes públicos del país, destacando la oposición que suscitan en las poblaciones aledañas y en la opinión pública nacional los efectos ambientales y sociales negativos generados por proyectos extractivistas (MAYOL, 2012; MORALES; TAMAYO, 2012; FERNÁNDEZ; SALINAS, 2012, entre otros). Paralelamente, se aprecia la reactivación de las organizaciones y las acciones ejecutadas por distintos actores sociales que articulan su cohesión en torno a lo local y fuera del sistema político representativo tradicional (BAROZET, 2011).

Al respecto destaca la relevancia que el patrimonio ha adquirido como dispositivo de reconocimiento y construcción grupal, también como categoría política y espacio de confrontación simbólica. Esto, en primer lugar, permite a los grupos reconocerse a sí mismos, representándose y materializándose socialmente a partir de sus experiencias, memoria y tradiciones, cuestionando la visión que otros proyectan sobre ellos para, enseguida, problematizar el concepto de desarrollo y enfrentar las visiones que sobre él plantean el Estado y las empresas.

Así, en ruptura pero de modo complementario a las tácticas de movilización colectiva clásicas usadas en escenarios reivindicativos y de disputa (TILLY, 1984), se detecta en el país el avance de una nueva forma de resistencia: la activación patrimonial de bienes naturales y culturales presentes en espacios en conflicto como forma de añadir valor simbólico a esos territorios y obstaculizar el accionar empresarial (LORCA; HUFTY, en prensa).

De esta forma, si antes las movilizaciones sociales en el país se vincularon al sistema de relaciones sociola- borales y al conflicto capital/trabajo, en la actualidad sucede que más bien se centran en la oposición capital/territorio, donde lo patrimonial se transforma en un recurso más para resolver las nuevas problemáticas, las amenazas y los conflictos que enfrentan las colectividades. En palabras de Rivera (2004: 10) se estaría frente a un "proceso de resemantización de las reivindicaciones laborales-sindicales hacia las reivindicaciones étnico patrimoniales-territoriales".

Sin embargo, que un proceso de patrimonialización sea emprendido no significa que este obligatoriamente termine siendo legitimado por la institucionalidad correspondiente. Pues, como plantea Rautenberg (2003), es preciso distinguir entre un patrimonio propiamente tal, "para la eternidad" y "duro", en tanto producto legalmente reconocido y protegido, y los contenidos patrimoniales de carácter "oportunista" y "blando" que los grupos locales activan, pero que no necesariamente se convertirán en un producto patrimonial legalmente certificado.

Ahora bien, esto tampoco resta validez al hecho de que una parte de las dinámicas de patrimonialización -entendidas como el proceso de aumento de la carga simbólica de ciertos elementos culturales y naturales- que se observan hoy en el país se dirijan a articular acciones que legitimen demandas que se orientan a lograr equidad y derechos específicos, la preservación del territorio y sus recursos naturales y la intervención de las poblaciones locales en decisiones que les competen. Es lo que manifiestan movimientos aparentemente tan disímiles como aquellos que en las ciudades tienen por objetivo la defensa del entorno y la calidad de vida barrial contra la presión inmobiliaria y las acciones ejecutadas por grupos indígenas para proteger su territorio contra los efectos negativos de la gran minería (PAULSEN, 2014; LORCA; HUFTY, en prensa). 


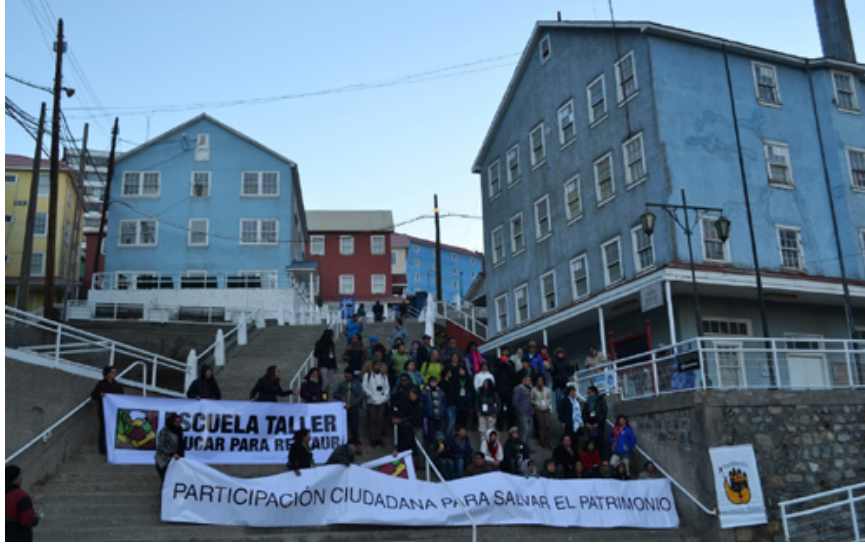

Visita al campamento minero de Sewell, patrimonio mundial, en el marco del $4 .^{\circ}$ Congreso de Barrios y Zonas Patrimoniales realizado en Machalí, Chile, 2015 I foto Asociación Chilena de Barrios y Zonas Patrimoniales

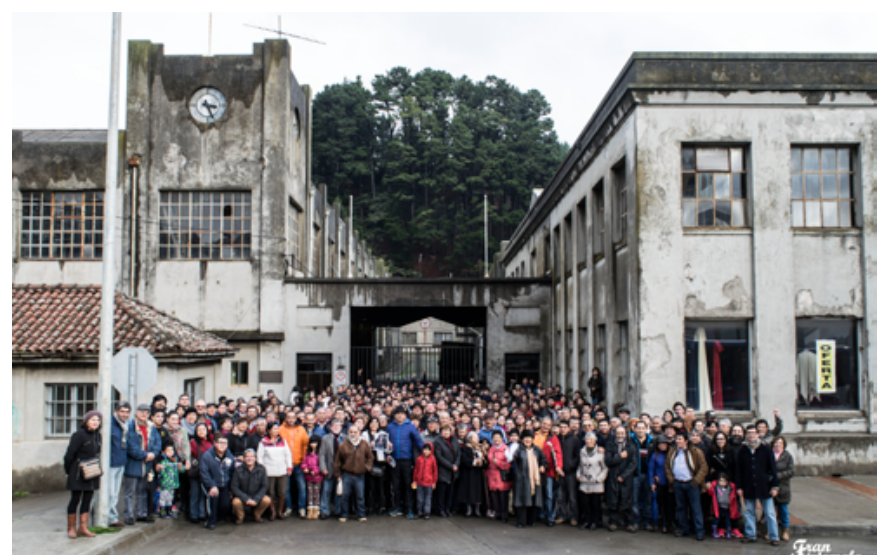

Fotografía tomada en mayo del 2016 frente a la fachada de la fábrica texti Bellavista-Tomé, que replica una imagen de 1935. Simboliza la lucha de la comunidad para que ese recinto sea reconocido legalmente como patrimonio nacional | foto Francisco Matamala, Mesa Ciudadana por el Patrimonio de Tomé

El patrimonio actualmente se convierte para grupos locales en una forma de acción política dirigida a construir y controlar sus espacios más próximos por medio del ordenamiento racional de estos y que su desarrollo responda a proyectos que obedezcan a modelos de entendimiento entre los distintos actores presentes en un territorio. De esta forma, el patrimonio se posiciona como un concepto central dentro de los conflictos y las negociaciones políticas que en muchos lugares sostienen las comunidades locales con el Estado y agentes empresariales del sector forestal, minero, pesquero o inmobiliario. Es a nivel local, a partir de las culturas y las tradiciones propias a cada grupo social, donde parte importante de la ciudadanía chilena actualmente está cohesionándose y organizándose, extendiendo de forma conceptual y aplicada la noción de patrimonio al otorgarle una función política.

\section{BIBLIOGRAFÍA}

- BAROZET, E. (2011) De la démobilisation au réinvestissement local. Mouvements sociaux locaux et territoires au Chili. Cahiers des Amériques Latines, n. ${ }^{\circ}$ 66, 2011, pp. 73-89

- FERNÁNDEZ, M.; SALINAS, J. (2012) Defensa de los derechos territoriales en Latinoamérica. Santiago de Chile: RIL Editores, 2012. 515 p.

- LORCA, M.; HUFTY, M. (en prensa) El patrimonio como forma de resistencia a la gran minería. El caso del Huasco Alto, Chile. Revista Intersecciones en Antropología

- MORALES, R.; TAMAYO, M. (ed.) (2012) Racionalidades en pugna. Pueblos indígenas originarios y empresas: Ambientes, economías $y$ culturas. Valdivia: Serindigena Ediciones; Ediciones Universidad Austral de Chile, 2012. 152 p.

- MAYOL, A. (2012) El derrumbe del modelo. La crisis de la economía de mercado en Chile contemporáneo. Santiago de Chile: LOM Editores, 2012. 165 p.

- PAUlSEN, A. (2014) Negocios inmobiliarios, cambio socioespacial y contestación ciudadana en Santiago Poniente. El caso del barrio Yungay. 2000-2013. En HIDALGO, R.; JANOSCHKA, M. (ed.) La ciudad neoliberal. Gentrificación y exclusión en Santiago de Chile, Buenos Aires, Ciudad de México y Madrid. Santiago de Chile: Pontificia Universidad Católica de Chile; Universidad Autónoma de Madrid, 2014, pp. 75-98

- RAutenberg, M. (2003) Comment s'inventent de nouveaux patrimoines: Usages sociaux, pratiques institutionnelles et politiques publiques en Savoie. Culture \& Musées, n. ${ }^{\circ}$ 1, 2003, pp. 19-40

- RIVERA, F. (2004) Antiflexibilización con identidad/alteridad. La cuestión étnica atacameña contemporánea y su contexto neoliberal flexible. Revista de Antropología Experimental, n. ${ }^{\circ}$ 4, 2004, pp. 1-17

- TILLY, C. (1984) Les origines du répertoire de l'action collective contemporaine en France et en Grande-Bretagne. Vingtième siècle. Revue d'histoire, n. ${ }^{\circ} 4$, 1984, pp. 89-108 